\title{
LOGÍSTICA DE COMBUSTÍVEIS E ANÁLISE ENVOLTÓRIA DE DADOS: AVALIAÇÃO DO DESEMPENHO DE UMA REDE DE POSTOS DO ALTO PARANAÍBA E TRIÂGULO MINEIRO
}

\section{FUEL LOGISTICS AND DATA ENVELOPMENT ANALYSIS: PERFORMANCE EVALUATION OF A GAS STATION ENTERPRISE NETWORK FROM ALTO PARANAÍBA AND TRIÂNGULO MINEIRO}

\author{
Maria Gabriela Mendonça Peixoto*E-mail: mgabriela@ufv.br \\ Bruno Eduardo Silva Lopes* E-mail: bruno eduardo963@hotmail.com \\ Vagner Alves Arantes* E-mail: vagner.arantes@ufv.br \\ Larissa Sousa Campos* E-mail: larissa.sousa@ufv.br \\ Maria Cristina Angélico Mendonça** E-mail: mariacam@ufla.br

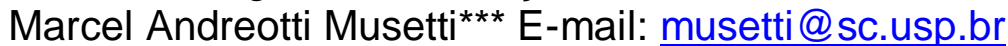 \\ *Universidade Federal de Viçosa (UFV - Campus Rio Paranaíba), Paranaíba, MG \\ **Universidade Federal de Lavras (UFLA), Lavras, MG \\ ${ }^{* * \star}$ Escola de Engenharia de São Carlos/Universidade de São Paulo (EESC/USP), São Paulo, SP
}

Resumo: O objetivo deste trabalho envolve avaliar o desempenho dos processos de escoamento de combustíveis de uma rede formada por oito postos, localizada na região do Triângulo Mineiro e Alto Paranaíba, por meio da aplicação da técnica de Análise Envoltória de Dados $(D E A)$. Para alcançar este objetivo, a eficiência foi calculada por meio da aplicação do modelo CCR com orientação para o output e, para tanto, foram utilizados dados secundários referentes aos anos de 2012 e 2013. O método de pesquisa utilizado foi o quantitativo, com um breve complemento da pesquisa qualitativa, $e$ abordagem de pesquisa exploratória; foram realizadas entrevistas sem a utilização de um questionário formalizado, via conversas de caráter profissional. Dos resultados obtidos, cabe destacar que apenas três, das oito DMUs, atingiram a fronteira de eficiência, isto é, 2 e 4, em 2012, e 2 e 6, em 2013. Neste contexto, pôde-se observar, portanto, importantes indícios de que a localização das $D M U$ s, e o porte de cada uma delas, não necessariamente exerce influência sobre a eficiência, mas sim em relação ao volume movimentado.

Palavras-chaves: Postos de Combustíveis. Eficiência. Desempenho Organizacional. Análise Envoltória de Dados.

Abstract: The aim of this paper involves evaluating the performance of fuel-flow processes of an enterprise network consisting of eight gas stations, located in the region of Triangulo Mineiro and Alto Paranaiba, through the application of Data Envelopment Analysis (DEA) technique. To achieve it, the efficiency was calculated by applying the CCR model with output orientation and, therefore, secondary data were used considering the years of 2012 and 2013. The research method used was the quantitative, with a brief complement of the qualitative research, and exploratory research approach; interviews were conducted without the use of a formalized questionnaire, via professional conversations. The results show that it is necessary to emphasize that only three of the eight DMUs have reached the efficient frontier, that is, 2 and 4, in 2012, and 2 and 6, in 2013. In this context, it may be observed, therefore, important evidences that the location of the DMUs, and also their sizes, not necessarily influence on the efficiency, but rather on the volume handled.

Keywords: Gas Stations. Efficiency. Organizational Performance. Data Envelopment Analysis. 


\section{INTRODUÇÃO}

Em um mercado que tem se tornado cada vez mais exigente e competitivo, cabe às empresas se adaptarem para melhorar os seus resultados financeiros, bem como a gestão, de forma eficiente, de seus custos. Em meio a essa concorrência acirrada, pequenos ganhos representam grandes diferenças para a sobrevivência das empresas no mercado. Assim, a minimização dos custos de operação e a maximização dos resultados têm sido os objetivos das empresas em todos os ramos de negócio (FAVARETTO, 2009).

Em postos de combustíveis, a minimização dos custos operacionais é essencial para o negócio, visto que é um ramo de atividade que possui altos custos e uma pequena margem de contribuição. Logo, a adequada gestão desses custos pode significar um grande diferencial entre seus concorrentes, nesse setor.

Assim, tem-se a importância da eficiência como otimização de recursos, e ausência de desperdícios, por meio da utilização máxima dos recursos existentes para satisfazer as necessidades e os desejos de indivíduos e organizações (PINDYCK; RUBINFELD, 1994). Para Peña (2008), a eficiência é a combinação ótima dos insumos e métodos necessários no processo produtivo, de modo que seja gerado o máximo nível de produtos, sendo englobada ainda, segundo Djellal e Gallouj (2009), pelo conceito de desempenho.

Nesse sentido Faria e Costa (2009) chamam a atenção para a capacidade de geração de valor que a logística pode agregar ao serviço. Assim, em se tratando dos custos com transporte de combustíveis, Figueiredo (2006) comenta que estes podem impactar em até $5,4 \%$ do preço na bomba, mais do que a margem de contribuição estimada para as empresas, que é de 1,5\% a 3\%. O alto custo com 0 transporte de combustíveis pode ser atribuído à precariedade do sistema logístico brasileiro, quando comparado ao de países como Rússia, Índia e Estados Unidos, e ao modal de transporte mais utilizado atualmente, isto é, o rodoviário (FIGUEIREDO, 2006; JAKITAS, 2012).

Frente ao cenário exposto, neste trabalho tem-se como objetivo avaliar o desempenho dos processos de escoamento de combustíveis de uma rede de postos localizada na região do Triângulo Mineiro e Alto Paranaíba, por meio da aplicação da técnica de Análise Envoltória de Dados. Assim, definiu-se como recorte o uso de dados referentes aos anos de 2012 e 2013. Para tanto, o trabalho encontra-se dividido em introdução, breve apresentação acerca da logística de combustíveis, contextualização do fluxo de combustíveis no país e gestão de desempenho em postos de combustíveis. Em seguida, são apresentados os procedimentos metodológicos utilizados para alcançar os resultados, finalizando-se com as conclusões, e as referências bibliográficas. 


\section{GESTÃO DE SERVIÇOS}

Vargo e Lush (2004) definem serviço como a aplicação de competências especializadas (habilidades e conhecimento), por meio de ações, processos e atuações para o benefício de outra entidade. Para Johnston e Clark (2008), o conceito de serviços envolve a proposição de um negócio para a empresa, ou seja, é como ela gostaria de ter seus serviços reconhecidos por seus clientes; já para o cliente, é o modo pelo qual ele percebe os serviços da empresa. Segundo Maldonado (2008) os serviços começaram a ganhar importância acadêmica a partir da década de 1950, quando nos Estados Unidos esse ramo representava aproximadamente $50 \%$ de sua economia.

Quanto às características dos serviços, Kotler (1994) define quatro aspectos básicos, a saber, intangibilidade, heterogeneidade, inseparabilidade e perecibilidade. A intangibilidade dos serviços é descrita como performances que não podem ser vistas, provadas, sentidas, ouvidas ou cheiradas, antes de serem compradas. Para Gianesi e Corrêa (1994), a intangibilidade pode ser verificada pelo fato dos serviços serem experiências que o cliente vivencia na hora da prestação do serviço, o que explica a dificuldade com que as empresas possuem para entender como seus consumidores percebem e avaliam a qualidade desses processos.

A heterogeneidade está relacionada à alta variabilidade existente entre a prestação/produção de um serviço e a prestação do seguinte, considerando que a simultaneidade, produto da presença do cliente, obriga o sistema de operações de serviços a customizá-lo para cada um (GRONROOS, 1993). Kotler (1994) também define heterogeneidade como a influência do desempenho na prestação de serviços, no que diz respeito a aspectos técnicos (conhecimentos, habilidades e suporte material) e emocionais (condições e características psicológicas), pelo lado do prestador de serviços. Uma característica peculiar dos serviços, em relação aos produtos físicos, é a inseparabilidade. Os serviços são inseparáveis de quem os executa ou fornece, de tal forma que o prestador faz parte do próprio serviço (KOTLER, 1994).

Quanto à perecibilidade, Kotler (1994) define os serviços como perecíveis, pois não podem ser estocados para a venda ou uso posterior, o que é um sério problema para a empresa que o oferece, quando a demanda é flutuante, como acontece nas que lidam com serviços de demanda cíclica, sazonal ou irregular. Nesse sentido, a capacidade ociosa do sistema de operações de serviço não pode ser eficientemente realocada, quando comparada a operações de manufatura (MALDONADO, 2008).

Em postos de combustíveis pode-se observar a presença constante de serviços envolvendo atividades como: troca de óleo, lava jato, borracharia, entre outros, e venda de produtos, que é caso dos combustíveis, de forma geral. Para Gianesi e Corrêa (1994), a avaliação da qualidade do serviço pelo cliente pode ocorrer em qualquer parte do processo de prestação de serviços, e dificilmente será 
feita antes da compra. Por outro lado, esta pode ocorrer em função das expectativas do cliente pelo serviço, complementam os autores.

Schiffman e Kanuk (2000) reforçam que a avaliação da qualidade dos serviços é mais difícil que a avaliação da qualidade dos produtos, devido às características que Kotler (1994) menciona em seu trabalho. Ao contrário dos produtos, grande parte dos serviços primeiramente é vendida, depois produzida e consumida, simultaneamente. Um produto defeituoso pode ser controlado durante a sua produção, um serviço defeituoso é consumido à medida que está sendo produzido, restando poucas chances de correção. A avaliação da qualidade dos serviços feita pelo consumidor é embasada em suas expectativas quanto ao serviço efetivamente prestado. Se a expectativa é superada, o consumidor tenderá a reconhece-la como sendo de alta qualidade (SCHIFFMAN; KANUK, 2000).

\subsection{Aspectos gerais da logística de combustíveis}

A logística pode ser entendida como o processo de gerenciamento estratégico da compra, do trânsito, e da armazenagem de matérias-primas, partes e produtos acabados, e de seus canais de marketing (CHRISTOPHER, 2008), sendo responsável por todo o processo de movimentação de materiais (ZANONI et al., 2013). Nesse sentido, Lambert, Stock e Vantine (1998) atentam para o fato de que a logística tem como objetivo a entrega do produto certo, no lugar e no momento certos, bem como nas condições e custos adequados, buscando pela satisfação do cliente para que este gere resultados econômicos para a empresa, no curto e longo prazos.

Para Fleury (2000) a gestão dos processos logísticos abrange o planejamento e o gerenciamento de todas as atividades envolvidas, desde a obtenção, fornecimento e transformação, à coordenação e colaboração com parceiros, que podem ser fornecedores, intermediários, provedores de serviços e clientes. Segundo Faria e Costa (2009), o profissional de logística precisa racionalizar as operações, introduzir e melhor aproveitar as tecnologias disponíveis, minimizar os custos de processamento de pedidos e compartilhar as informações e serviços entre os membros da cadeia.

No contexto da logística de combustíveis, Esteves e Bicalho (2008) apresentam três tipos de fluxos na distribuição, a saber, partindo do fluxo primário composto pelas refinarias e usinas de álcool, para as bases de distribuição; os fluxos de transferências entre as diferentes bases; e os fluxos de entrega, com saída das bases para os clientes. A distribuição de combustíveis automotivos é realizada pelo transporte ferroviário e rodoviário, enquanto para o varejo as entregas são realizadas, quase totalmente, por rodovias, e sempre em curta distância (MALIGO, 2005; FIGUEIREDO, 2006).

Assim, cabe destacar a importância da localização das bases de distribuição de combustíveis. $O$ correto dimensionamento dessas instalações tende a reduzir o tempo de espera dos caminhões-tanque que levarão 0 produto ao cliente, 
proporcionando um maior número de viagens e resultando na otimização de recursos (ESTEVES; BICALHO, 2008). Além disso, tendo em vista o caráter estratégico e a influência das bombas de combustíveis sobre o funcionamento dos postos, tem-se que a agilidade no atendimento corretivo desses equipamentos também refere-se a um dos grandes desafios enfrentados pelo varejo de combustíveis (SELLITTO et al., 2015).

\subsection{Contextualização da produção de combustíveis no Brasil}

O Brasil pode ser considerado um grande consumidor e produtor de combustíveis, visto que, segundo a Agência Brasil (2014), o país consumiu, no ano de 2012, cerca de 129,6 bilhões de litros ao passo que, no ano posterior, pôde-se notar um aumento da ordem de $5 \%$ no consumo, alcançando o patamar de 136,2 bilhões de litros. Dessa forma, para atender a tal demanda, o país conta com 16 refinarias, 365 usinas de etanol, 299 importadores e exploradores de petróleo e derivados, 138 produtores de lubrificantes, 172 importadores de lubrificantes, 19 refinadores de lubrificantes, e 66 produtores de biodiesel (AGÊNCIA NACIONAL DE PETRÓLEO, GÁS NATURAL E BIOCOMBUSTÍVEIS, 2013).

A Figura 1 ilustra a estrutura do sistema nacional de abastecimento de combustíveis. Como pode ser observado, antes de chegar ao consumidor final, o produto passa pelas refinarias que são os produtores, ou usinas, no caso de biocombustíveis, seguindo até as distribuidoras. Destas, os combustíveis seguem para os TRRs (Transportador Revendedor Retalhista), empresas que vendem óleo diesel a retalho, ou para os postos de combustíveis.

Figura 1 - Sistema Nacional de Abastecimento de Combustíveis

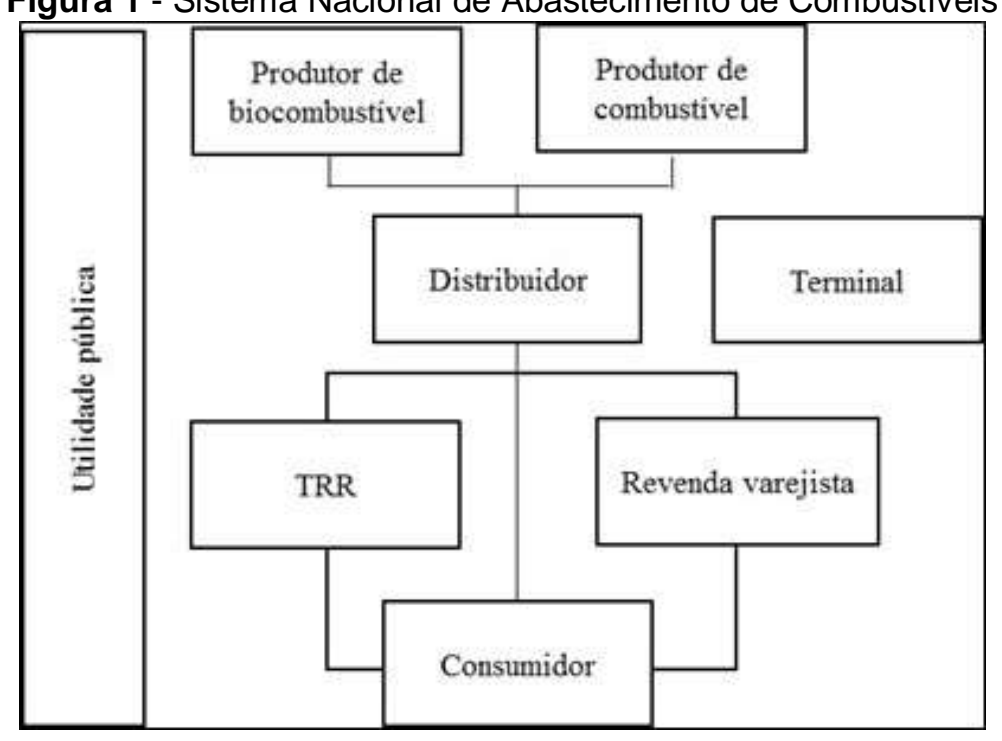

Fonte: Adaptada pelos autores de ANP (2013)

Quanto aos custos logísticos, Figueiredo (2006) aponta que o Centro de Estudos em Logística estima que os gastos com combustíveis no Brasil se aproximem dos 2 bilhões ao ano, valor este que pode ser explicado novamente pela 
precariedade logística do país e pelo modal de transporte mais utilizado, o rodoviário. Para tanto, em consequência da concentração de demanda, a maior oferta de modais alternativos está nas Regiões Sul e Sudeste, como os dois principais canais para transporte de combustíveis, a saber, o Oleoduto São PauloBrasília, e o Paraná-Santa Catarina (WERNECK; RODRIGUES, 2013).

Conforme a Figura 2 torna-se possível perceber que o Brasil possui uma estrutura logística inferior, quando comparada a países como Rússia e Índia, mas principalmente à China, visto que suas malhas rodoviária e hidroviária representaram, em 2012, apenas $13,25 \%$ e $12,73 \%$ da infraestrutura chinesa. No caso da Índia, embora esse país apresente extensão hidroviária semelhante à brasileira e seja praticamente um terço menor que o Brasil, sua extensão rodoviária significa sete vezes a brasileira e a ferroviária, mais que o dobro. Em relação à Rússia, o Brasil apresenta apenas, $21,2 \%$ de sua rede rodoviária, 33,3\% da ferroviária e, 14\% da hidroviária (JAKITAS, 2012).

Figura 2 - Comparativo do Brasil em relação Índia, China e Rússia, envolvendo os canais logísticos rodoviário, hidroviário e ferroviário

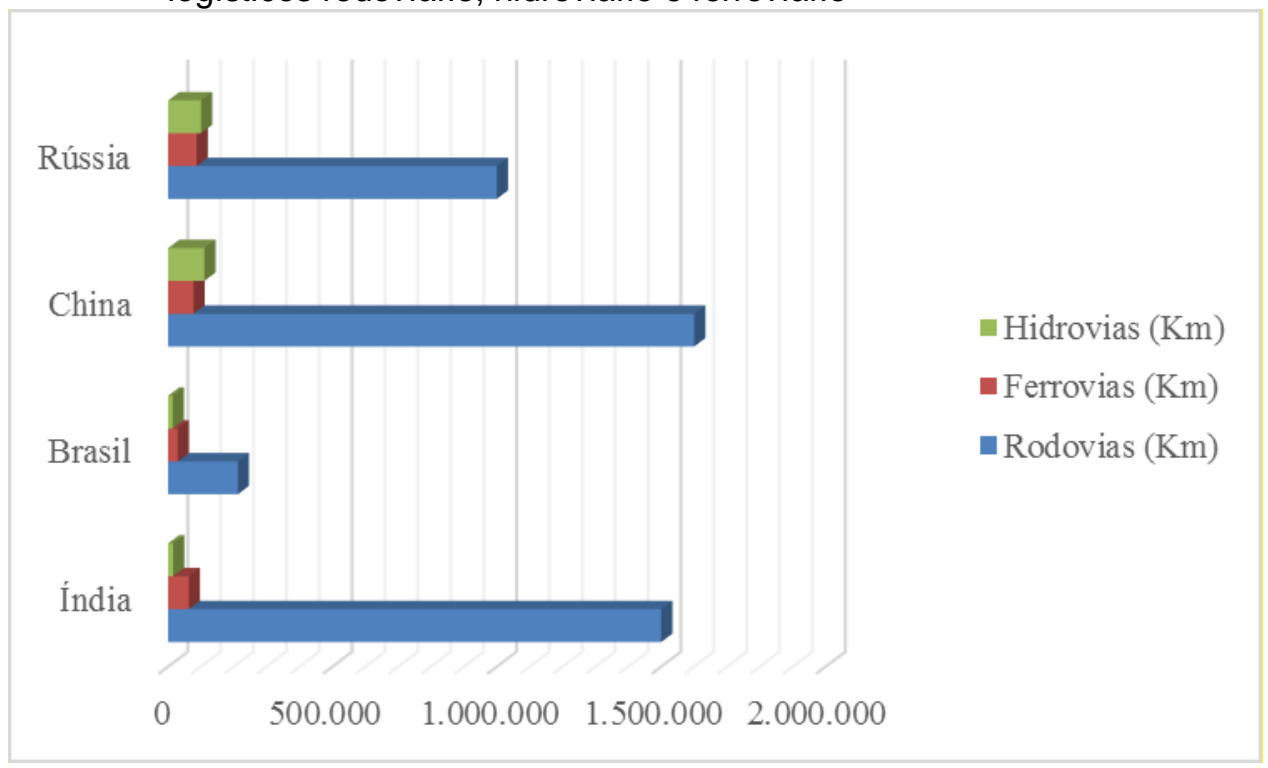

Fonte: Adaptada de Jakitas (2012)

Em consequência da concentração de demanda, a maior oferta de modais alternativos concentra-se nas Regiões Sul e Sudeste, como os dois principais dutos para transporte de combustíveis o Oleoduto São Paulo-Brasília, e o Oleoduto Paraná-Santa Catarina (WERNECK e RODRIGUES, 2013). Ainda segundo esses autores, as principais ferrovias também estão situadas nessas regiões; a Ferrovia Centro-Atlântica (FCA), que liga a Refinaria Gabriel Passos (Regap), em Betim (MG), às bases secundárias do interior de Minas Gerais; ALL Malha Paulista, ligando a Refinaria de Paulínia (Replan), ao interior de São Paulo e à Região Centro-Oeste; e a ALL Malha Sul, que liga a Refinaria do Paraná (Repar), em Araucária (PR), e a Refinaria Alberto Pasquelini (Refap), em Canoas (RS), ao interior de seus respectivos Estados. O transporte feito por hidrovias ocorre apenas na região Norte 
do Brasil e, a cabotagem, principalmente entre os Portos de Santos (SP) e Itaqui (MA).

Quanto à distribuição de combustíveis em Minas Gerais, tem-se sua origem na REGAP, em Betim, enquanto seus destinos são as demais cidades do Estado. Contudo, nem sempre o combustível segue diretamente para os municípios, pois a partir da refinaria podem-se ter fluxos para bases localizadas em regiões estratégicas, geralmente cidades pólos de micro ou mesorregiões, sendo delas distribuído às demais cidades. O uso de cidades polos como entreposto de distribuição justifica-se devido ao fato de que quase sempre essas são cidades referências na região, sendo as de melhor acessibilidade e por serem quase sempre as cidades de maior demanda. Dessa forma, concentrando-se os fluxos para essas cidades, os custos de transporte por economia de escala são reduzidos (MOREIRA; MARTINS; SILVA, 2009).

\section{GESTÃo DE DESEMPENHO ORGANIZACIONAL EM POSTOS DE COMBUSTÍVEIS}

Em qualquer organização é desejável que o comportamento operacional seja compatível com a estratégia competitiva. Uma forma de verificar se o processo está funcionando dentro do esperado, se demanda melhorias ou ajustes, dá-se através de indicadores que monitorem as atividades que agregam valor, ou indicadores de desempenho (MARRAS, 2012). Um modelo de análise de desempenho acrescenta Bortoluzzi, Ensslin e Ensslin (2011), permite verificar os resultados alcançados e o impacto de estratégias adotadas pela empresa em diferentes dimensões.

No setor de serviços, o desempenho remete ao giro de estoque e à logística interna da empresa, podendo ser medido por indicadores como quantidade de entregas realizadas no prazo, tempo de entrega, quantidade de entregas não efetivadas, etc. (CONCEIÇÃO; QUINTÃO, 2004). Nesse contexto, Carvalho (2011) afirma que um dos segmentos mais competitivos é o de postos de combustíveis, principalmente em cidades pequenas, onde há muita similaridade nos preços dos produtos.

Em postos de abastecimento, Gagné, Nguimbus e Zaccour (2004) caracterizam os vendedores de combustíveis enquanto importante indicador de desempenho, bem como ressaltam a influência do número de postos sobre o desempenho organizacional, no que diz respeito à competição local. Png e Reitman (1994) complementam que o desempenho também pode sofrer reflexos de aspectos mercadológicos como preço, capacidade do serviço, e horas de funcionamento. Assim, a medição do desempenho nessas organizações acentua-se em função do papel estratégico que assumem, superando a simples condição de distribuidores de produtos derivados do petróleo (ASAYESH; RAAD, 2014). 


\section{PROCEDIMENTOS METODOLÓGICOS}

Marconi e Lakatos (2007) afirmam que a pesquisa é um procedimento formal com método de pensamento reflexivo, que requer tratamento científico e se constitui no caminho para se conhecer a realidade ou para descobrir verdades parciais. $\mathrm{Na}$ concepção das autoras, a finalidade da pesquisa é descobrir as respostas para as questões levantadas, por meio de métodos científicos.

Para que se tornasse possível atingir os objetivos propostos, utilizou-se a Análise Envoltória de Dados (DEA), a partir da aplicação do modelo CCR de Charnes, Cooper e Rhodes (1978). Adotou-se esse modelo, pois se pretendeu realizar, neste artigo, apenas um comparativo clássico acerca da eficiência produtiva global das DMUs, dando ênfase ao período de dois anos. Logo, vai além deste trabalho uma análise envolvendo retornos variáveis de escala e demais modelo $D E A$ complementares, tais como a identificação de outliers e de componentes de eficiência, apostando-se nestes enquanto propostas para trabalhos futuros.

Considerando-se que neste trabalho propôs-se a avaliar o desempenho logístico de postos de combustíveis, definiu-se sua orientação para o output, uma vez que esta se apoia na maximização das saídas resultantes dos postos, indo além da perspectiva de redução dos inputs consumidos em função dos processos de fornecimento de combustíveis. A formulação matemática para o modelo CCR encontra-se representada pela Figura 3.

Figura 3 - Formulário DEA para o modelo CCR com orientação ao output

$$
\begin{gathered}
\text { Minimizar } \sum_{i=1}^{r} v_{i} x_{i o} \\
\text { Sujeito a } \\
\sum_{i=1}^{m} u_{j} y_{j k}-\sum_{i-1}^{r} v_{i} x_{i k} \leq 0 \\
\sum_{j-1}^{s} u_{j} y_{j o}=1 \\
u_{j}, v_{i} \geq 0 \\
y=\text { produtos; } x=\text { insumos } ; u, v=\text { pesos } ; k=D M U \mathrm{~s} \\
j=1, \ldots, m ; i=1, \ldots, s ; k=1, \ldots, n
\end{gathered}
$$

Fonte: Adaptada pelos autores de Ferreira (2009) 
Conforme pode ser observado, o conjunto de fórmulas supracitado demonstra que o modelo tem como ponto de partida a minimização do somatório dos insumos da $D M U$ objetivo, multiplicados por seus respectivos pesos, sendo os inputs representados por $i=1, \ldots, r$, e os outputs por $j=1, \ldots, s$, bem como $u$ e $v$, os pesos, e $h_{k}$, o índice de eficiência. Além disso, o primeiro conjunto de restrições do modelo CCR pode ser entendido como o resultado apresentado pela empresa, tendo em vista a subtração dos produtos das DMUs pelos inputs, ressaltando-se que se espera que tal restrição seja igual a um, para que a $D M U$ seja eficiente. A segunda restrição demonstra que o maior resultado possível refere-se à unidade, ou seja, se $h_{k}$ for menor que um então a $D M U$ é considerada ineficiente, ao passo que, se for igual a um, encontra-se sobre a fronteira de eficiência (FERREIRA, 2009; KASSAI, 2002).

A definição dos inputs e outputs obedeceu ao que propõe a técnica $D E A$, ou seja, o número de DMUs participantes da análise deve representar, no mínimo, o dobro do somatório das variáveis de entrada e saída (LIN; HONG, 2006; LIN; TSENG, 2007). Nesse sentido, neste trabalho estão presentes três inputs e um output devendo definir, portanto, pelo menos oito unidades de análise, de forma que foram determinados oito postos de combustíveis.

Dessa forma, considerando-se os fatores de produção da empresa analisada, foram estabelecidos os inputs, volume de combustíveis comprados (litros), capacidade de armazenagem (litros) e número de funcionários envolvidos nas atividades operacionais da empresa (unidades). Já para a condição de output, foi determinado o volume de vendas de combustíveis, nos anos de 2012 e 2013. Tratam-se dos únicos indicadores de desempenho cedidos pela matriz da rede de postos, podendo ser considerada uma provável limitação enfrentada pelos pesquisadores para realização do trabalho. Essas variáveis foram, portanto, tabuladas através do software Sistema Integrado de Apoio à Decisão V3.0 (SIAD).

A Tabela 1 esquematiza algumas das informações básicas relativas aos 8 postos de combustíveis participantes deste trabalho. Com o intuito de preservar a imagem das empresas, optou-se por denominá-las $D M U$, numeradas de 1 a 8 . Quanto às bandeiras, essas foram classificadas em Alfa, Beta e Gama. Assim, as bandeiras Alfa e Beta apresentam marcas diferentes, enquanto a bandeira Gama representa ausência de bandeira, ou bandeira branca. As DMUs encontram-se localizadas nas regiões do Alto Paranaíba e do Triângulo Mineiro. 
Tabela 1 - Características básicas das DMUS

\begin{tabular}{lccc}
\hline DMUs & Bandeira & $\begin{array}{c}\text { Frota de veículos do município } \\
\text { (unidades) }\end{array}$ & Localização \\
\hline$D M U 1$ & Alfa & 17.118 & Rodovia \\
DMU 2 & Alfa e Beta & 9.434 & Rodovia \\
BMU 3 & Beta e Gama & 17.118 & Saída da Cidade \\
$D M U 4$ & Alfa & 55.948 & Saída da Cidade \\
$D M U 5$ & Alfa & 88.051 & Saída da Cidade \\
$D M U 6$ & Alfa & 88.051 & Saída da Cidade \\
$D M U ~ 7$ & Alfa & 9.434 & Saída da Cidade \\
DMU 8 & Gama & 17.118 & Centro da Cidade \\
\hline
\end{tabular}

Fonte: Adaptada pelos autores de IBGE (2013)

O método de pesquisa utilizado foi o quantitativo, tendo em vista o forte apoio na técnica matemática, com um breve complemento da pesquisa qualitativa, além da abordagem de pesquisa exploratória. A análise qualitativa pôde ser atingida por meio da observação do dia a dia da empresa, bem como da realização de entrevistas junto aos responsáveis pelos setores de compras e logística, via conversas de caráter profissional. Dessa forma, tornou-se possível descrever o fluxo logístico de combustíveis da região, tendo em vista o levantamento de variáveis qualitativas complementares à análise quantitativa. Os dados para execução do trabalho foram extraídos direto do sistema operacional utilizado pela empresa. Logo, foram utilizados dados secundários.

\section{ANÁLISE DA EFICIÊNCIA ORGANIZACIONAL POR MEIO DA APLICAÇÃO DO MODELO CCR}

Os resultados gerados pela $D E A$ surpreenderam ao indicar que todas as $D M U s$ estão próximas de atingir a fronteira da eficiência, considerando-se pequenos ajustes a serem feitos por algumas delas. Conforme descrito na metodologia do trabalho, as DMUs analisadas fazem parte de uma rede de postos de combustíveis, com portes totalmente diferentes, e ainda sim, apresentaram resultados semelhantes. Na Tabela 2 é possível verificar a eficiência calculada pelo modelo, para 2012 e 2013, em relação a todas as DMUs. 
Tabela 2 - Resultados gerados pela $D E A$ por meio da aplicação do modelo CCR com orientação para o output

\begin{tabular}{lccc}
\hline \multirow{2}{*}{ DMUs } & \multicolumn{2}{c}{ Eficiência } & Variação \% \\
\cline { 2 - 3 } DMU1 & $\mathbf{2 0 1 2}$ & $\mathbf{2 0 1 3}$ & \\
DMU2 & 0,954682 & 0,997798 & 4,52 \\
$D M U 3$ & 1 & 1 & - \\
$D M U 4$ & 0,996523 & 0,987742 & $-0,88$ \\
$D M U 5$ & 1 & 0,998423 & $-0,16$ \\
$D M U 6$ & 0,979535 & 0,999707 & 2,06 \\
$D M U 7$ & 0,981708 & 1 & 1,86 \\
$D M U 8$ & 0,997230 & 0,994671 & $-0,26$ \\
\hline
\end{tabular}

Apesar de cada $D M U$ ser independente, todas as atividades administrativas estão concentradas em uma única unidade, a qual encontra-se posicionada estrategicamente de modo a ficar o mais próxima possível de todos os postos. Assim, as políticas operacionais como de compras, armazenagem, crédito e cobrança, e treinamento e seleção de funcionários, das DMUs, são tratadas de forma homogênea pela matriz administrativa, fato que poderia contribuir para a explicação acerca do comportamento dos índices de eficiência.

Ao longo da realização da pesquisa, foi possível evidenciar que a bandeira utilizada pela $D M U$ não influencia na sua eficiência, visto que a $D M U 8$ não possui bandeira e ainda sim está próxima de atingir a fronteira. Já a DMU2 trocou de bandeira no final do ano de 2012, o que não impediu que essa $D M U$ fosse considerada eficiente tanto em 2012, quanto em 2013. Constatou-se também que o tamanho da frota da cidade onde a $D M U$ está localizada não influencia na eficiência, e nem no volume movimentado, mas o fator localização. Um exemplo envolve o fato de a DMU2 ter sido eficiente nos 2 anos analisados, e se encontrar na cidade com a menor frota, da ordem de 9.434 veículos, segundo dados do IBGE (2012), caracterizando-se como a unidade de análise que mais movimentou combustíveis por estar localizada em uma rodovia próxima à cidade.

Quanto ao porte das unidades, das que se mostraram eficientes em 2012 e 2013 (2, 4 e 6), as DMUs 4 e 6 não representam as que mais movimentaram combustíveis. Apesar de apresentarem uma movimentação relativamente inferior a 2, estas também atingiram a fronteira, o que evidencia que o porte da $D M U$ não exerceu influência sobre a eficiência que ela possa apresentar. É provável que, em se tratando de eficiência de escala, a $D M U$ com maior movimentação apresente uma eficiência maior que as demais, entretanto, a eficiência de escala não se encontra inserida entre os objetivos traçados para este trabalho.

\subsection{Síntese dos alvos para os inputs e outputs nos anos de 2012 e 2013}

Para se atingir os objetivos deste trabalho, um dos indicadores utilizados foi a capacidade de armazenagem, em função de sua influência direta sobre as vendas. 
Quanto maior a capacidade de armazenamento, maior será a disponibilidade de produtos para o consumidor final, embora nem sempre a DMU com maior capacidade de armazenamento seja a mais eficiente. Nota-se que a DMU1 detém a maior capacidade de armazenamento, 150.000 Its, enquanto a DMU3 possui a menor.

Como pode ser observado no Gráfico 1, em relação a 2012, o modelo propôs uma redução da capacidade de armazenagem para as $D M U s$ s 1,5 e 8 , indicando que parte dos estoques poderia estar sendo subutilizado, nesse ano. A redução da capacidade de armazenamento, proposta pelo modelo para a DMU1, é de 150.000 para $86.238,75$ litros, ou seja, uma redução de $42,51 \%$ da capacidade de armazenagem.

Gráfico 1 - Síntese dos alvos para a capacidade de armazenagem das DMUs em 2012

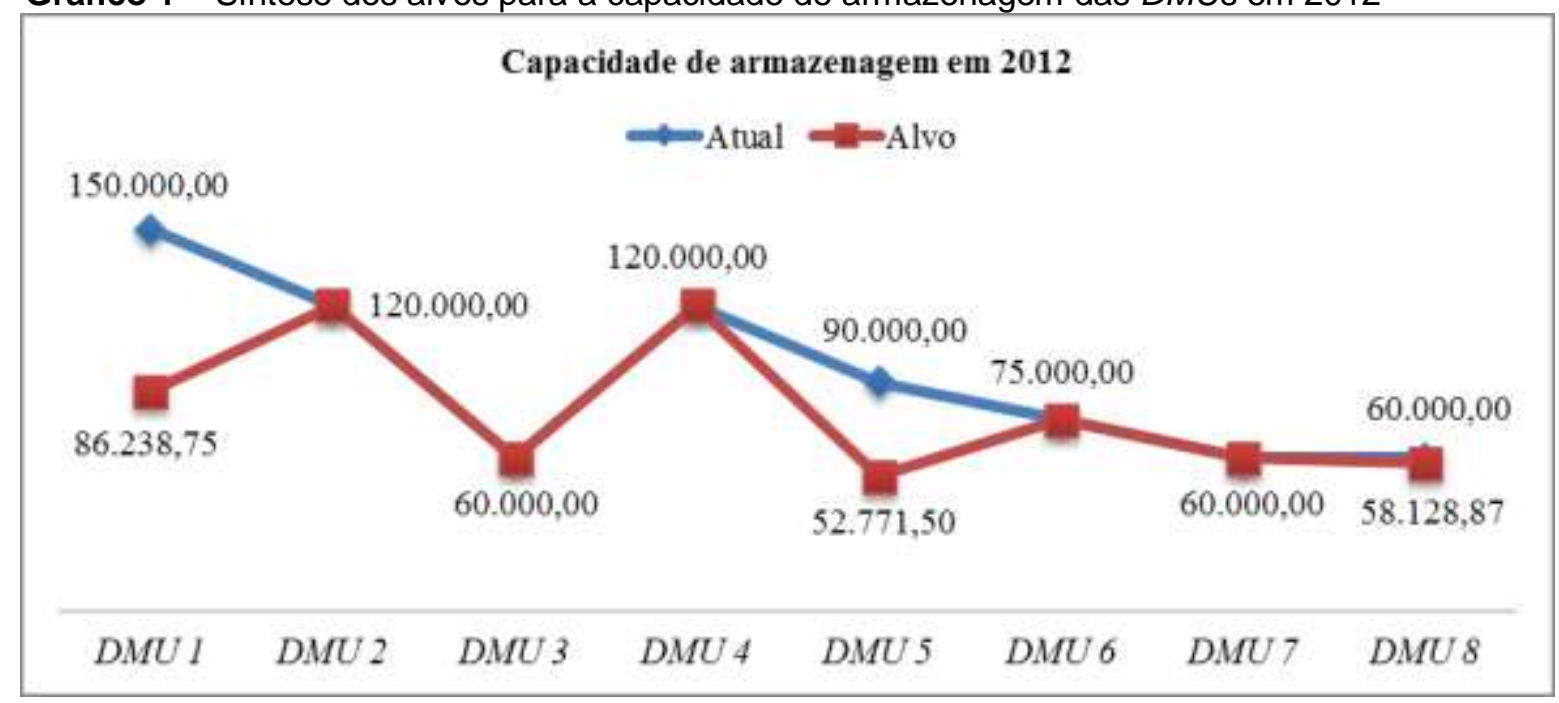

Já o Gráfico 2 demonstra que, em 2013, o modelo propõe uma redução para essa mesma $D M U$ de $20,72 \%$, passando de 150.000 para $118.915,13$ litros. Caso a empresa tivesse acatado a sugestão do modelo, em 2012, o seu giro de estoques, em 2013, poderia ter sido comprometido, pois teria que girar mais vezes para atender à demanda em 2013, já que a capacidade de armazenamento seria de $32.676,38$ litros a menos em relação a 2012, aumentando a frequência de compras, impactando nos custos como fretes, seguros e no resultado. 
Gráfico 2 - Síntese dos alvos para a capacidade de armazenagem das DMUs em 2013

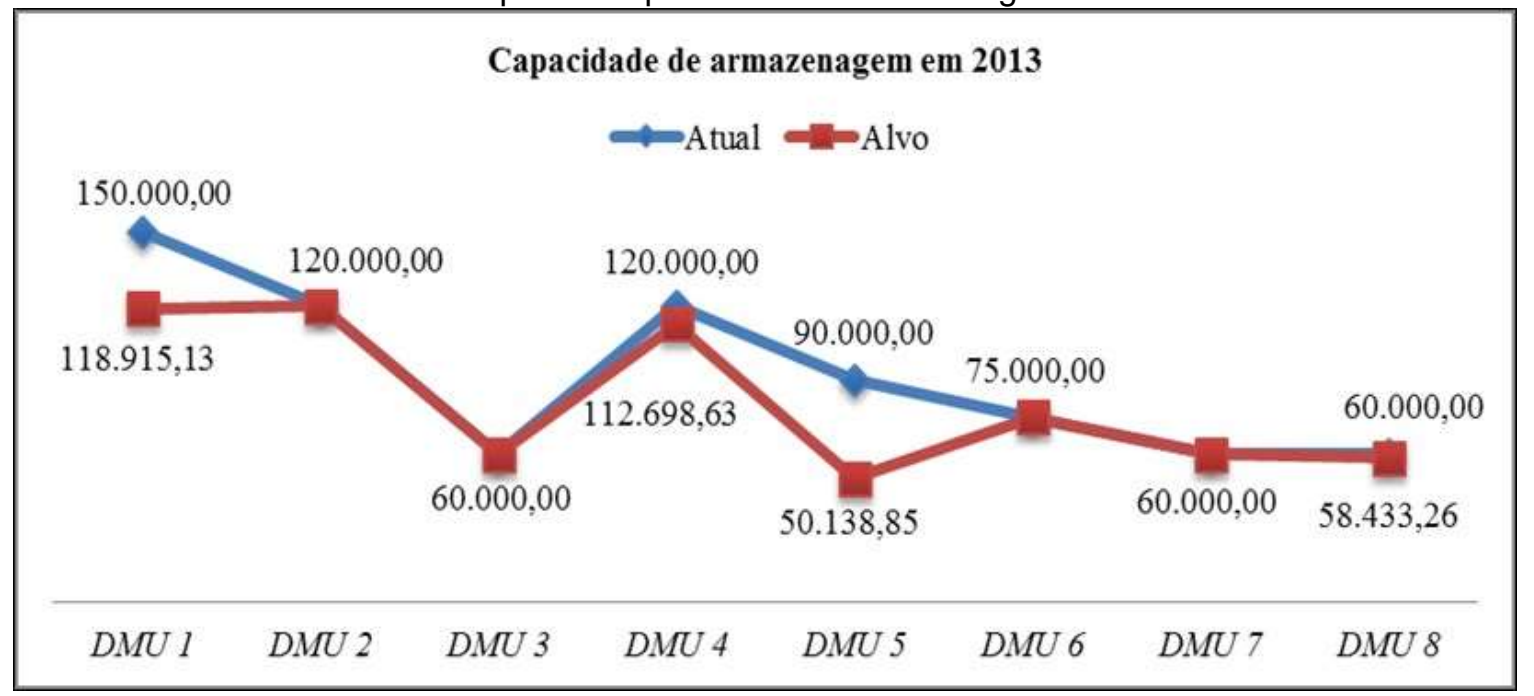

A diferença entre os alvos supracitados pode ser explicada pelo fato de que o volume movimentado, de 2012 para 2013, por essa DMU, aumentou em 51,48\%. Para as DMUs 5 e 8, a proposta feita pelo modelo em 2012 envolve, respectivamente, de $41,37 \%$ e $3,12 \%$ ao passo que, para 2013 , a proposta de redução envolve $44,29 \%$ e $2,61 \%$. Para a DMU8, as alterações sugeridas pelo modelo não se aplicam, visto que a diferença na "litragem" dos tanques é de $1.871,13$, em 2012, e de $1.566,74$, em 2013, e que cada tanque de armazenamento tem, no mínimo, 10.000 litros de capacidade. A proposta de redução da capacidade de armazenamento para a DMU5, em 2012 e 2013, se manteve relativamente constante, apresentando apenas uma leve variação de 2,92\%. O volume de combustíveis movimentado por essa $D M U$, em 2013 , foi de $0,61 \%$, superior a 2012 , ou seja, uma variação de menos de $1 \%$, o que explica o modelo propor para 2013 , uma redução semelhante à de 2012.

Em relação à quantidade de funcionários envolvidos nas operações das $D M U s$, esta pode implicar no volume de combustíveis movimentados. Assim, quanto maior o volume, maior poderá ser o número de funcionários envolvidos. Entretanto, observando a quantidade de funcionários das DMUs nota-se que a 1 apresentou, em 2012, a mesma quantidade de funcionários que a 2, mas apresentou um volume de combustíveis movimentados $71,47 \%$ menor que a DMU2. A DMU4 foi a que apresentou a maior variação no seu quadro de funcionários para os 2 anos. Inicialmente, esta apresentava 15 funcionários, em 2012, e em 2013, 20. A variação da DMU4 pode ser explicada pelo aumento de $38,23 \%$ no volume de combustíveis movimentados.

A DEA propôs ainda uma redução do quadro de funcionários, em 2012 (Gráfico 3), para a maioria das DMUs, excetuando-se 2 e 4, por estarem próximas à fronteira de eficiência desse ano, e para a DMU8. Segundo o Gráfico 4, o modelo também propôs redução do quadro de funcionários apenas para as $D M U s$ s, 5 e 7 . Em relação a 2012, entre as DMUs que terão que diminuir o quadro de funcionários para alcançar a fronteira de eficiência, se destacam as DMUs 1 e 5 , cabendo 
reduzir, respectivamente, de 19 funcionários para 11 (42,06\%) e, de 13 funcionários para 7 (48,08\%). Para 2013, o modelo não propôs alterações quanto à quantidade de funcionários, que passou de 19, em 2012, para 21, em 2013, o que pode ser explicado pelo grande aumento no volume movimentado que essa $D M U$ apresentou em relação ao primeiro ano analisado. Para a DMU5 o modelo propõe a redução de 6 funcionários, em 2012, e de 4 funcionários, em 2013. Tal mudança da proposta pode ser devido à unidade apresentar um aumento de $0,61 \%$ da quantidade de combustíveis movimentados.

Gráfico 3 - Síntese dos alvos para o número de funcionários das DMUs em 2012

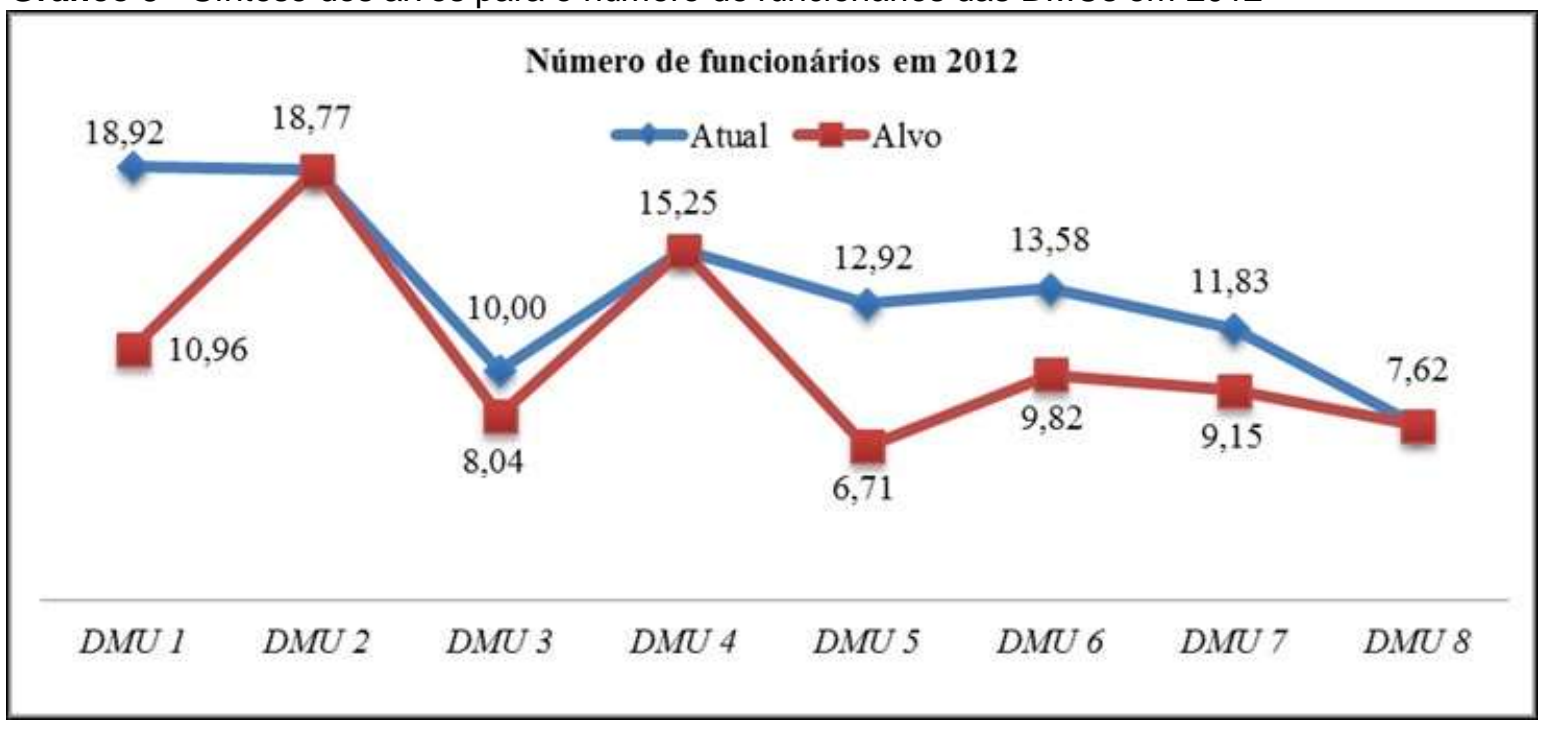

Gráfico 4 - Síntese dos alvos para o número de funcionários das DMUs em 2013

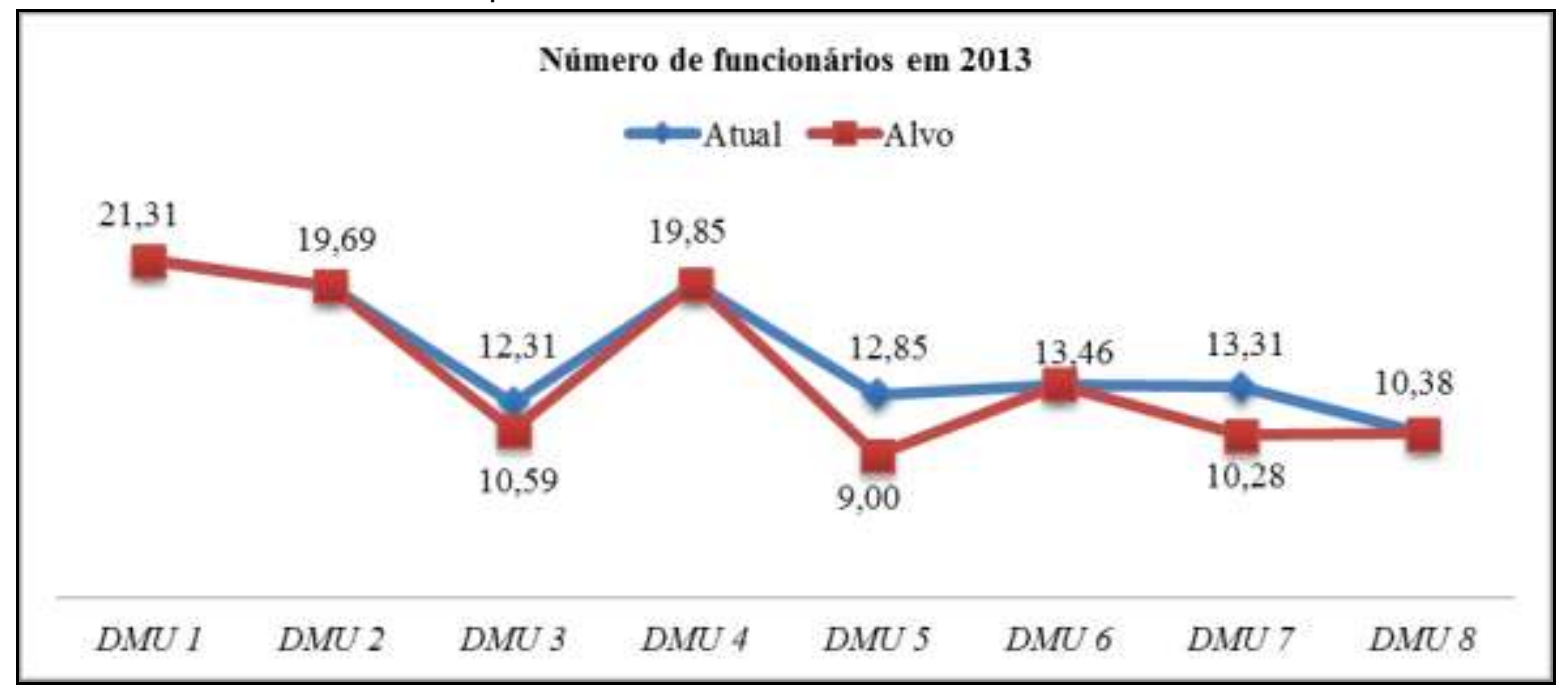

Quanto ao output quantidade de saída de combustíveis, as DMUs que mais se destacaram são 2 e 5, assim como no volume de compra dos combustíveis. O modelo propõe alterações para todas as DMUs nos 2 anos analisados, exceto para as DMUs que se encontram na fronteira da eficiência, conforme ilustrado nos Gráficos 5 e 6 . Dessa forma, para que possam se tornar eficientes, a $D E A$ sugere às 
demais que aumentem o seu volume de vendas. $O$ ano de 2012 foi o que apresentou as maiores alterações a serem feitas pelas DMUs, com destaque para as DMUs 1 e 5, que deverão aumentar o seu volume de vendas em $4,75 \%$ e 2,09\%, respectivamente.

Gráfico 5 - Síntese dos alvos para o volume de combustíveis vendidos em 2012

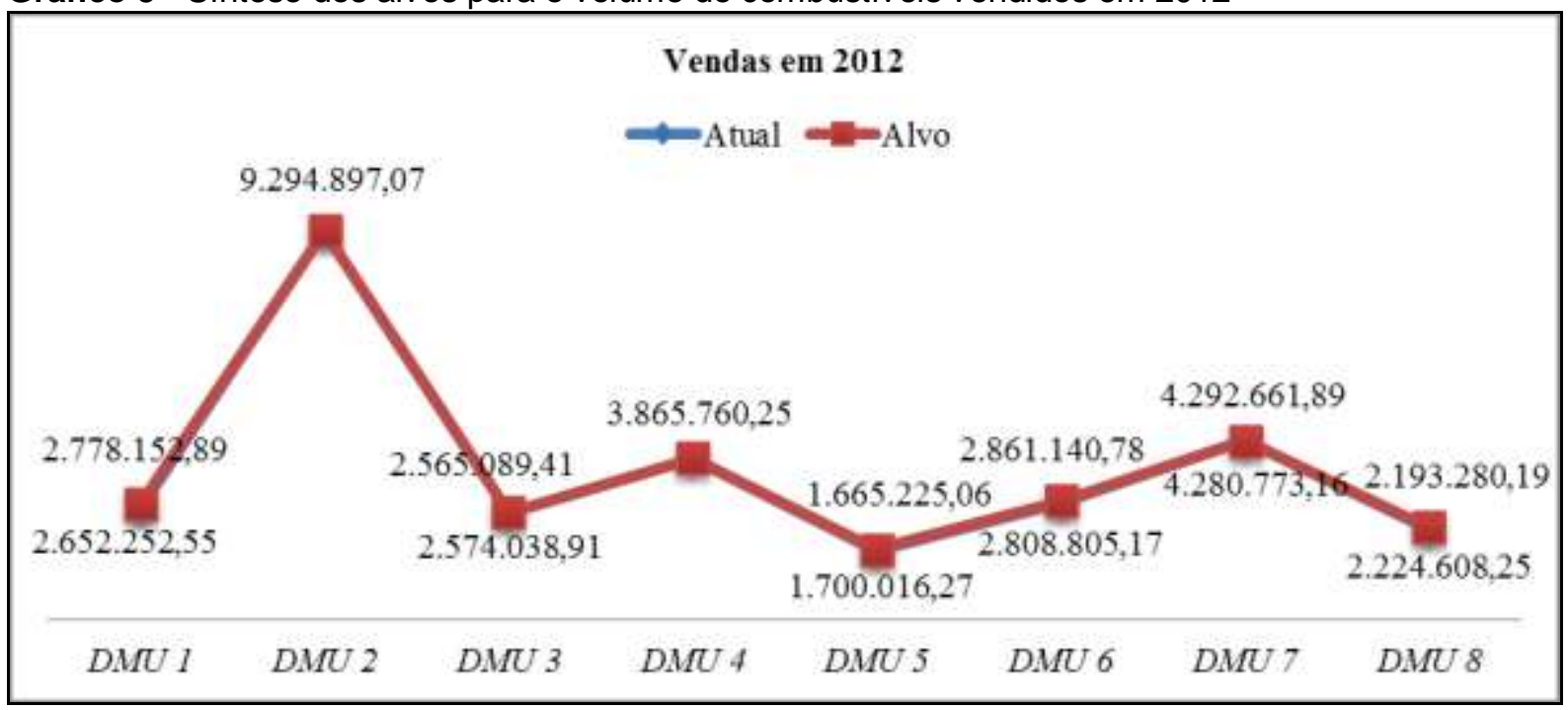

Gráfico 6 - Síntese dos alvos para o volume de combustíveis vendidos em 2013

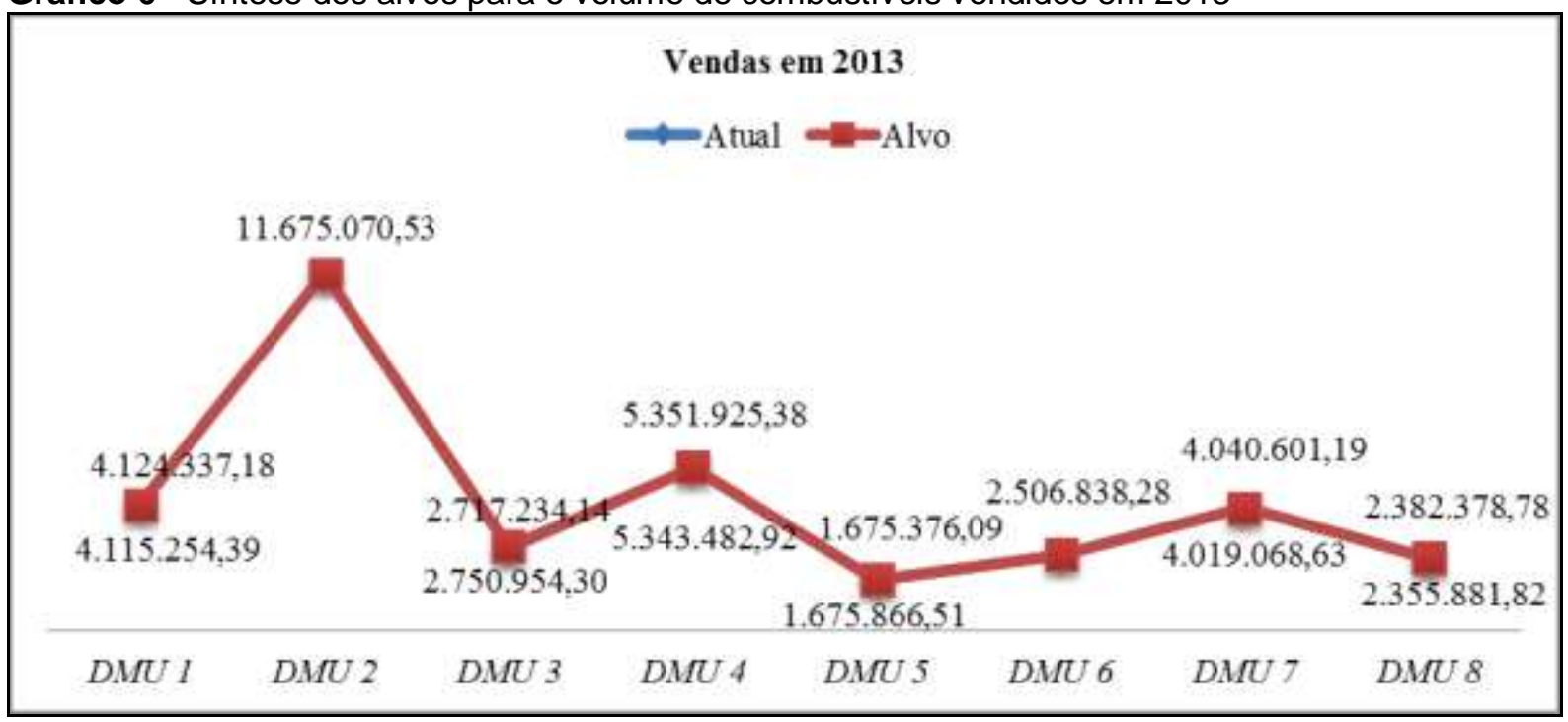

Por fim, em 2013, apesar da DMU1 ter superado a proposta do modelo em 2012, em 50,41\% este propõe, para 2013, um aumento no volume de vendas de $0,22 \%$. Para se tornar eficiente, cabe à DMU1 aumentar seu volume de vendas mesmo ultrapassando o valor proposto em 2012, pois, para atingir o volume movimentado em 2013, esta não utilizou de forma eficiente os seus inputs. Assim, para a DMU5 cabe, para o ano de 2013, um aumento no volume de vendas de apenas $0,03 \%, 98,60 \%$ menor em relação a 2012, indicando que, em 2013, essa unidade utilizou os seus inputs de forma mais eficiente. 


\section{CONCLUSÕES}

A aplicação do modelo CCR permitiu observar que apenas três, das oito DMUs, atingiram a fronteira de eficiência, isto é, 2 e 4, em 2012, e 2 e 6, em 2013. Assim, as propostas geradas pela $D E A$ para a tomada de decisão na empresa devem ser analisadas cuidadosamente, visto que se baseiam em dados que já aconteceram, ou seja, a eficiência foi calculada com base em fatos do passado, não prevendo alterações que ainda possam acontecer bruscamente no mercado. Para a DMU1, em 2012, o modelo propôs a redução dos estoques em $42,51 \%$ e, em 2013 , o volume movimentado por essa $D M U$ aumentou em $51,48 \%$, reforçando-se que, caso a empresa tivesse acatado a proposta do modelo, em 2012 o atendimento de toda a demanda do ano de 2013, possivelmente poderia ter sido comprometida.

Com a aplicação do modelo foi possível verificar que a localização das DMUs e o porte de cada uma delas não influenciaram na eficiência, mas sim no volume movimentado. Apesar da grande diferença de porte entre as DMUs, todas ficaram próximas do alcance da fronteira de eficiência. Por fim, reforça-se a grande contribuição para este trabalho, e para a rede de empresas analisada, do apoio em dados financeiros, pois por meio deles poderiam ser gerados índices ainda mais confiáveis e precisos. Como pesquisas futuras sugere-se o cálculo das eficiências técnica pura e de escala, buscando-se reforçar, ainda mais, o cenário da eficiência organizacional das DMUs analisadas.

\section{REFERÊNCIAS}

AGÊNCIA BRASIL. 2014. Disponível em:

$<$ http://agenciabrasil.ebc.com.br/economia/noticia/2014-03/anp-consumo-de-combustiveisno-brasil-cresceu-5-em-2013>. Acesso em: 22 nov. 2014.

AGÊNCIA NACIONAL DE PETRÓLEO, GÁS NATURAL E BIOCOMBUSTÍVEIS - ANP. Abastecimento em números. Boletim gerencial. Informações sobre a comercialização de combustíveis. v.8, n. 42, 2013.

ASAYESH, R.; RAAD, Z. F. Evaluation of the relative efficiency of gas stations by data envelopment analysis. International Journal of Data Envelopment Analysis and ${ }^{*}$ Operations Research*, v. 1, n. 1, p. 12-15, 2014.

BORTOLUZZI, S. C.; ENSSLIN, S. R., ENSSLIN, L. Avaliação de desempenho multicritério como apoio à gestão de empresas: aplicação em uma empresa de serviços. Gestão \& Produção, v. 18, n. 3, p. 633-650, 2011.

CARVALHO, P. L. C. Análise da qualidade do serviço de um posto de gasolina do município de Machado-MG. Enciclopédia Biosfera, Centro Cientifico Conhecer-Goiânia, v. 7, p. 6, 2011.

CHARNES, A.; COOPER, W. W.; RHODES, E. Measuring the efficiency of decision-making units. European Journal Operational Research, v. 2, p. 429-444, 1978. 
CHRISTOPHER, M. Logística e gerenciamento da cadeia de suprimentos. 2. ed. São Paulo: Cengage Learning 2008.

CONCEIÇÃO, S. V.; QUINTÃO, R. T. Avaliação do desempenho logístico da cadeia brasileira de suprimentos de refrigerantes. Belo Horizonte: UFMG, 2004.

DJELLAL, F.; GALLOUJ, F. Measuring and improving productivity in services: issues, strategies and challenges. Edward Elgar Publishing, 2009.

ESTEVES, H. B. B.; BICALHO, L. N. Aspectos técnico-econômico da logística da distribuição de combustíveis no Brasil. In: RIO OIL \& GAS EXPO AND CONFERENCE 2008, 2008, Rio de Janeiro. Anais... Rio de Janeiro, 2008. Disponível em:

<http://www.anp.gov.br/?dw=58912>. Acesso em: 2 de maio de 2015.

FARIA, A. C.; COSTA, M. de F. G. Gestão de custos logísticos. São Paulo: Atlas 2009.

FAVARETTO, F. Impacto dos parâmetros de controle de estoques na falta de produtos em prateleiras (stockout). Disponível em:

<http://www.convibra.com.br/artigo.asp?ev=25\&id=4513>. Acesso em 05 de agosto de 2014 .

FERREIRA, C. M. de C. Introdução à análise envoltória de dados: teoria, modelos e Aplicações. Viçosa, MG: Editora UFV, 2009.

FIGUEIREDO, R. Gargalos logísticos na distribuição de combustíveis brasileira.

Disponível em: <http://www.coppead.ufrj.br/pt-

br/upload/publicacoes/ArtLog_MAI_2006.pdf/>. Acesso em: 20 de outubro de 2014.

FLEURY, P.F. Logística empresarial: a perspectiva brasileira. 1. ed. São Paulo: 1a ed., Atlas, 2000.

GAGNÉ, R.; NGUIMBUS, R.; ZACCOUR, G. The effects of location and non-location factors on gasoline station performance. Energy Studies Review, v. 12, n. 2, 2004.

GIANESI, I. G. N.; CORRÊA, H. L. Administração Estratégica de Serviços: Operações para a Satisfação do Cliente. São Paulo: Atlas, 233p., 1994.

GRONROOS, C. Marketing, gerenciamento e serviços: a competição por serviços na hora da verdade. Rio de Janeiro: Campus, 1993.

JAKITAS, R. Brasil precisa triplicar investimentos para melhorar logística, 2012. Disponível em: <http://veja.abril.com.br/noticia/brasil/brasil-precisa-triplicar-investimentospara-melhorar-logistica/>. Acesso em: 20 de novembro de 2014.

KASSAI, S. Utilização da análise por envoltória de dados (DEA) na análise de demonstrações contábeis. 2002. Tese (Doutorado em Contabilidade e Controladoria) Universidade de São Paulo, São Paulo, 2002.

KOTLER, P. Administração de marketing: análise, planejamento, implementação e controle. 4. ed. São Paulo: Atlas, 1994.

LAMBERT, D. M.; STOCK, J. R.; VANTINE, J. G. administração estratégica da logística. Vantine Consultoria, 1999. 
LIN, L. C.; HONG, C. H. Operational performance evaluation of international major airports: An application of data envelopment analysis. Journal of Air Transport Management, v. 12, n. 6, p. 342-351, 2006.

LIN, L. C.; TSENG, C. C. Operational performance evaluation of major container ports in the Asia-Pacific region. Maritime Policy \& Management, v. 34, n. 6, p. 535-551, 2007.

MALDONADO, M. U. Análise do impacto das políticas de criação e transferência de conhecimento em processos intensivos em conhecimento: um modelo de dinâmica de sistemas. 2008, p.138 Dissertação (Mestrado em Engenharia e Gestão do Conhecimento). Programa de Pós-graduação em Engenharia e Gestão de Conhecimento. Universidade Federal de Santa Catarina, (UFSC), Florianópolis, 2008.

MALIGO, C. Modelo para simulação da operação de carregamento de caminhões: tanque em uma base de distribuição de combustíveis automotivos. Rio de Janeiro, Dissertação de mestrado, Pontifícia Universidade Católica do Rio de Janeiro PUCRJ, 2005.

MARCONI, M. de A.; LAKATOS, E. M. Fundamentos de metodologia científica. 6.ed.São Paulo: Atlas, 2007

MARRAS, J. P. Avaliação de desempenho humano. Elsevier Brasil, 2012.

MOREIRA, B. C. de M.; MARTINS, R. S.; SILVA, G. J. C. da. Perspectivas da contribuição do transporte ferroviário à eficiência da distribuição de combustíveis (álcool, diesel e gasolina) em Minas Gerais DOI 10.5752/P. 1984-6606.2009 v9n20p45. Revista Economia \& Gestão, v. 9, n. 20, p. 45-72, 2009.

PEÑA, C. R. Um modelo de avaliação da eficiência da administração pública através do método Análise Envoltória de Dados (DEA). Revista de Administração Contemporânea, Curitiba, Paraná, v. 12, n. 1, p. 83-106, 2008.

PINDYCK, R. S e RUBINFELD, D. L. Microeconomia: teoria microeconômica. Makron Books, São Paulo, 1994.

PNG, I. P. L.; REITMAN, D. Service time competition. The Rand Journal of Economics, p. 619-634, 1994.

SCHIFFMAN, L. G.; KANUK, L. L. Comportamento do consumidor. 6. ed. Rio de Janeiro: LTC, 2000.

SELLITTO, M. A.; DE OLIVEIRA, L.; PEREIRA, G. M.; BORCHARDT, M. Localização de bases de assistência técnica de um prestador de serviços de manutenção de bombas de combustível. Revista Produção Online, v. 15, n. 1, p. 2-20, 2015.

VARGO, S. L.; LUSCH, R. F. Evolving to a new dominant logic for marketing. Journal of Marketing, n. 68, 2004.

ZANONI, G.; LIMA, E. P.; MATTIODA, R.; DA COSTA, S. E. G. Modelo para avaliação de níveis de maturidade na relação comprador-fornecedor: um estudo de fornecedores da indústria automobilística. Revista Produção Online, v. 13, n. 2, p. 703-736, 2013.

WERNECK, M.; RODRIGUES, C. Transporte de combustíveis no Brasil: investimentos para o abastecimento até 2020. Revista Tecnologística. 2013. Disponível em: 
<http://www.ilos.com.br/ilos_2014/publicacoes/artigos-2013/transporte-de-combustiveis-nobrasil-investimentos-para-o-abastecimento-ate-2020/> Acesso em 25 de outubro de 2014.

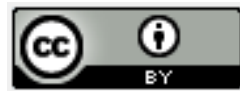

Artigo recebido em 31/01/2016 e aceito para publicação em 04/08/2016

DOI: http://dx.doi.org/ 10.14488/1676-1901.v16i3.2339 